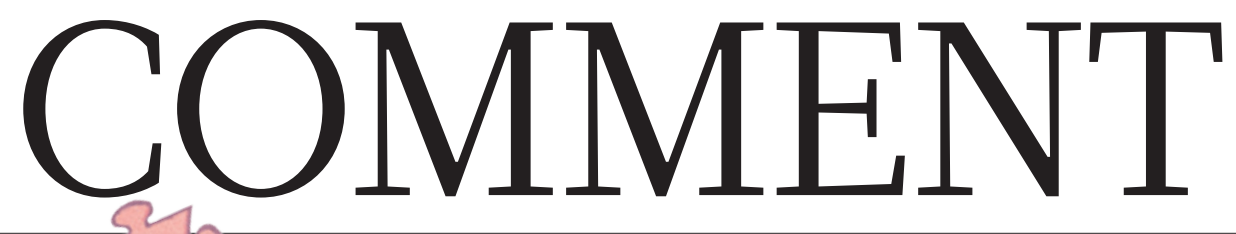

MENTAL health Collaborative $\square$ Vaccines The dramatic tale research needed to improve 25 of two typhus biologists psychological treatments $\mathbf{p . 2 8 7}$ under the Nazis p.291
CAREERS Virtual mobility will drive equal opportunities for scientists in Europe $\mathbf{p . 2 9 2}$
EDUCATION Top graduates volunteer to teach China's rural poor $\mathbf{p . 2 9 2}$

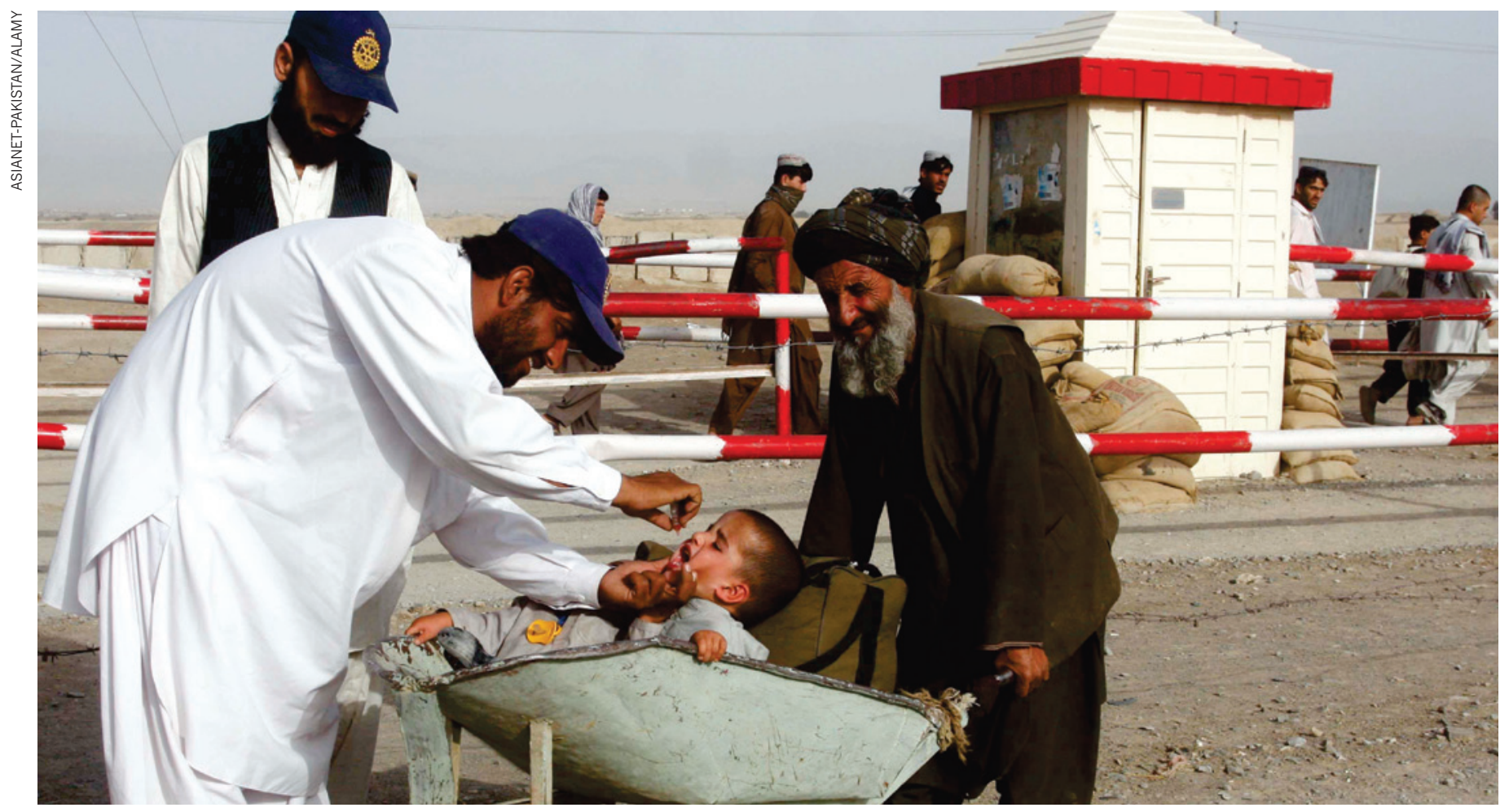

A health worker gives a dose of polio vaccine to a child in Chaman, Pakistan, near the Afghan border, in May.

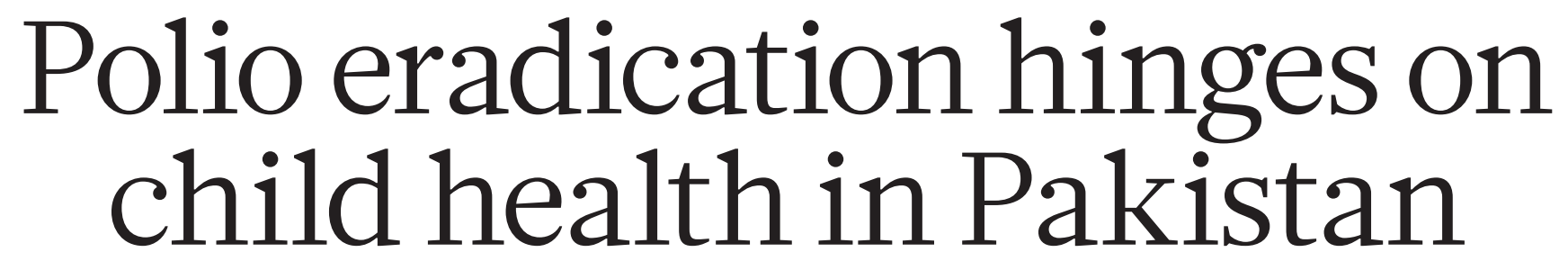

Boosting basic medical services and routine immunizations - not travel vaccinations - is the key to ending polio worldwide, says Zulfiqar Ahmed Bhutta.

$\mathrm{U}$ ntil about a year ago, a world free
of poliomyelitis seemed to be
imminent. In 1988 , about 350,000 people in 125 countries became paralysed by the virus. Last year, only 406 cases were reported, with 160 of them in just a few areas of the three countries where polio remains endemic: Afghanistan, Nigeria and Pakistan. In April 2013, charities and governments pledged US $\$ 4$ billion to a six-year plan developed by the World Health Organization (WHO) to eradicate polio. In March, after India had gone three years with no new cases, the WHO certified its southeast Asia region (which does not include Afghanistan and Pakistan) as polio-free.

But in May, the WHO declared polio an international public-health emergency, particularly because of the high risk of international spread from Pakistan, Cameroon and Syria (see go.nature.com/ 7z3efj). Disrupted vaccination programmes in war-torn places are partly to blame.

Confronted by this, the WHO took an unprecedented step: it called for mandatory polio vaccination for everyone travelling to or from Pakistan, Syria and Cameroon, and encouraged travel vaccinations for Afghanistan, Nigeria and others ${ }^{1}$. Formal international travel restrictions for Pakistan began on 1 June. Analyses in the past few years show $^{2}$ that symptom-free adults transmit polio at surprisingly high rates. However, computer modelling described ${ }^{3}$ earlier this month suggests that immunizing adults to control an outbreak is less effective than previously believed.

In my view, vaccinating travellers will be ineffective and it could make polio $>$ 


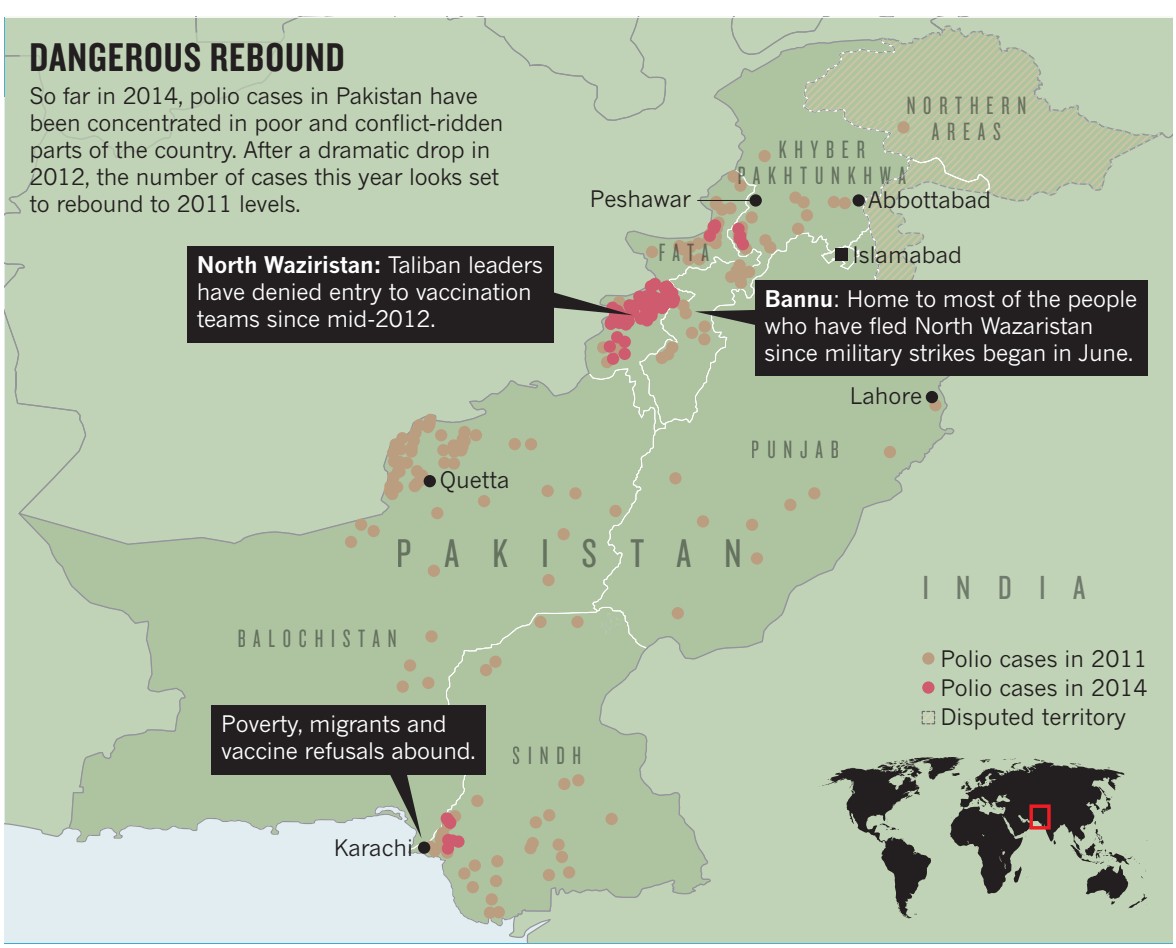

$>$ harder to eliminate in the poor and conflict-ridden parts of Pakistan. It is largely here that the final battle to eradicate polio from the world will be won or lost.

Cases of polio in Pakistan increased from 18 in the first six months of 2013 to 88 in the first half of 2014 (ref. 4). Of these, 75\% were in the regions known as the Federally Administered Tribal Areas (FATA) in the northwest (see 'Dangerous rebound'). Here, access for polio-vaccination teams is severely restricted by conflict and insecurity.

Since mid-June, the situation has worsened. In the wake of government military action against Taliban insurgents, more than 800,000 people from Waziristan in the FATA have been displaced to neighbouring parts of Pakistan and Afghanistan. Instead of focusing on the vaccination of international travellers, Pakistan, the WHO and immunization services should provide immediate health care to displaced families and others in these high-risk areas.

\section{PRECIOUS DOSES}

Federal and provincial governments in Pakistan have scrambled to set up vaccination points at all ports and airports, and at more than 130 public hospitals. The government of Punjab, Pakistan's richest and most populous province, also rushed to impose vaccination requirements for the main routes of entry. The federal government made polio vaccination mandatory at major entry and exit points in the FATA, especially in North Waziristan, although much of the long, troubled border with Afghanistan is unpatrolled.

Official sources estimate that more than 10 million doses are needed just for the air travellers entering or exiting Pakistan each year, including the roughly 7 million Pakistani citizens who work overseas, mostly as labourers in the Middle East. The donor community has provided 200,000 doses of injectable polio vaccine for refugees, but no further financial support has been pledged for more doses or for trained staff to perform vaccinations and issue certificates to adult travellers at public hospitals.

So far, the only service offered for free to travellers is the oral vaccine from the supplies of national polio programmes. (Some 300 million doses of oral polio vaccine, mostly furnished by the United Nations children's charity UNICEF, are needed annually to vaccinate young children in Pakistan.) Pakistan's army requested 60,000 doses of inactivated injectable polio vaccine as a priority for its troops. Adults must buy this type of vaccine privately at a cost of $\$ 4.30$ per dose - a huge expense in an area where the average monthly income is about $\$ 100$. Newspapers report that getting a vaccination certificate is as difficult and expensive as getting a visa. An industry of fake certification could emerge.

There is no precedent to predict how well these travel restrictions will work. I travelled out of Karachi airport on 6 and 15 June. Although vaccination counters had been set up, I saw no queues of travellers waiting to receive polio vaccines, and no one asked me for a vaccination card at any of the multiple checkpoints. Furthermore, polio transmission from Pakistan to Afghanistan occurs mostly across an unregulated border.

Meanwhile, Pakistan's efforts to vaccinate young children have fallen behind. Some of the blame can be pinned on the ill-planned abolition of its ministry of health in 2011 and the subsequent devolution of health services to the provinces. Although the ministry was reinstated last year and federal polio efforts are now back in operation, they are still weak.

That said, Pakistan deserves much more credit than it has received for its past work to eradicate polio, especially in its troubled tribal regions: it has staged more than 130 national and regional polio-immunization efforts since it began house-to-house vaccination campaigns in 2000 .

But the emphasis on polio, to the neglect of other health services, has long fuelled beliefs that polio immunization is an external initiative operating for outsiders' benefit. AntiWestern sentiment has led to repeated attacks on polio-eradication workers, volunteers and security personnel; more than 80 have been killed since December 2012. This year, polio teams have been hit by roadside bombs and by gunmen on motorcycles. In March, a Pakistani polio worker was kidnapped and shot.

Resistance to polio campaigns is more entrenched and violent in Pakistan than in most other countries. Disastrously, mobilevaccination teams came under more suspicion than ever ${ }^{5}$ after it emerged that the US Central Intelligence Agency had staged a fake hepatitis $B$ vaccination project in the Pakistani city of Abbottabad in 2011 to try to trace Osama bin Laden.

Although international Islamic scholars have spoken up for polio eradication, support for it from local religious and society leaders on the ground has been, at best, lukewarm. In the 1980s and 90s, warring factions in Latin America and in Africa agreed to 'days of tranquility' to permit mass polio immunizations. In Pakistan, by contrast, a handful of Taliban leaders in the tribal areas of North Waziristan and the Khyber Agency have, since mid-2012, denied entry to vaccination teams as a protest against US drone strikes.

In May this year, the Pakistani army moved to provide security to vaccination teams in the FATA, but it has not offered support to other mainstream health workers. This and the hastily imposed travel regulations will only give credence to claims that polio eradication is part of a foreign agenda.

\section{PRESCRIPTION PACKAGE}

Providing polio vaccines as part of a package of health services is a better way to engage local communities and religious leaders than through a narrow, polio-specific programme. Nigeria and Afghanistan have made remarkable progress in reaching difficult populations in this way, and cases dropped by about $60 \%$ in both nations from 2012 to $2013^{4}$. The Taliban do not actively keep children from being immunized for measles or from receiving care for diarrhoea or malnutrition.

Currently, Pakistan has one of the highest rates of child mortality in south Asia ${ }^{6}$. 
Children face much bigger health threats than polio. But immunization services for major childhood diseases such as diphtheria, tetanus and measles remain plagued with inefficiencies, poor oversight and a shortage of resources.

Full immunization rates for children in the country were last year estimated at $54 \%$ with wide variations across the country ${ }^{7}$, compared to more than $95 \%$ in nearby Bangladesh. The figures for Pakistan may even be an overestimate: the survey excluded the FATA and vulnerable populations in mega-cities. In a household survey conducted this year, my colleagues and I found that $25 \%$ of children under five years in the urban slums of Karachi were not vaccinated for any childhood disease; the same was true for $64 \%$ of children in a relatively peaceful district of the FATA.

The time to act is now. The military offensive in North Waziristan has, paradoxically, opened up opportunities to provide health services to children from the FATA through care for displaced families. This could contribute to building community support and to re-establish the rule of law in conflict-ridden areas once people return. Ongoing support will be necessary to eradicate polio: children require multiple doses of vaccine to build immunity.

I fervently hope that the government and concerned agencies will devote their energies to scaling up full immunization efforts in these displaced and marginal populations, rather than diverting resources to international travellers. This is a chance to eradicate polio from the planet.

Zulfiqar Ahmed Bhutta is director of the Center of Excellence in Women and Child Health at the Aga Khan University in Karachi, Pakistan, and co-director of the Sick Kids Center for Global Child Health in Toronto, Canada.

e-mail:zulfiqar.bhutta@aku.edu

1. Rutter, P. D. \& Donaldson, L. J. Lancet 383, 1695-1697 (2014).

2. Mayer, B. T. et al. Am. J. Epidemiol. 177, 1236-1245 (2013).

3. Blake, I. M. et al. Proc. Natl Acad. Sci. USA http://dx.doi.org/10.1073/ pnas.1323688111 (2014)

4. Independent Monitoring Board of the Global Polio Eradication Initiative Ninth Report May 2014 (Global Polio Eradication Initiative, 2014).

5. Bhutta, Z. A. Br. Med. J. 346, f280 (2013).

6. Bhutta, Z. A. et al. Lancet 381, 2207-2218 (2013).

7. National Institute of Population Studies and ICF International Pakistan Demographic and Health Survey 2012-13 (NIPS \& ICF International, 2013).

The views expressed are those of the author alone, and do not necessarily reflect those of any institution with which he is affiliated. The author declares competing financial interests: see go.nature.com/cnhjcu for details.

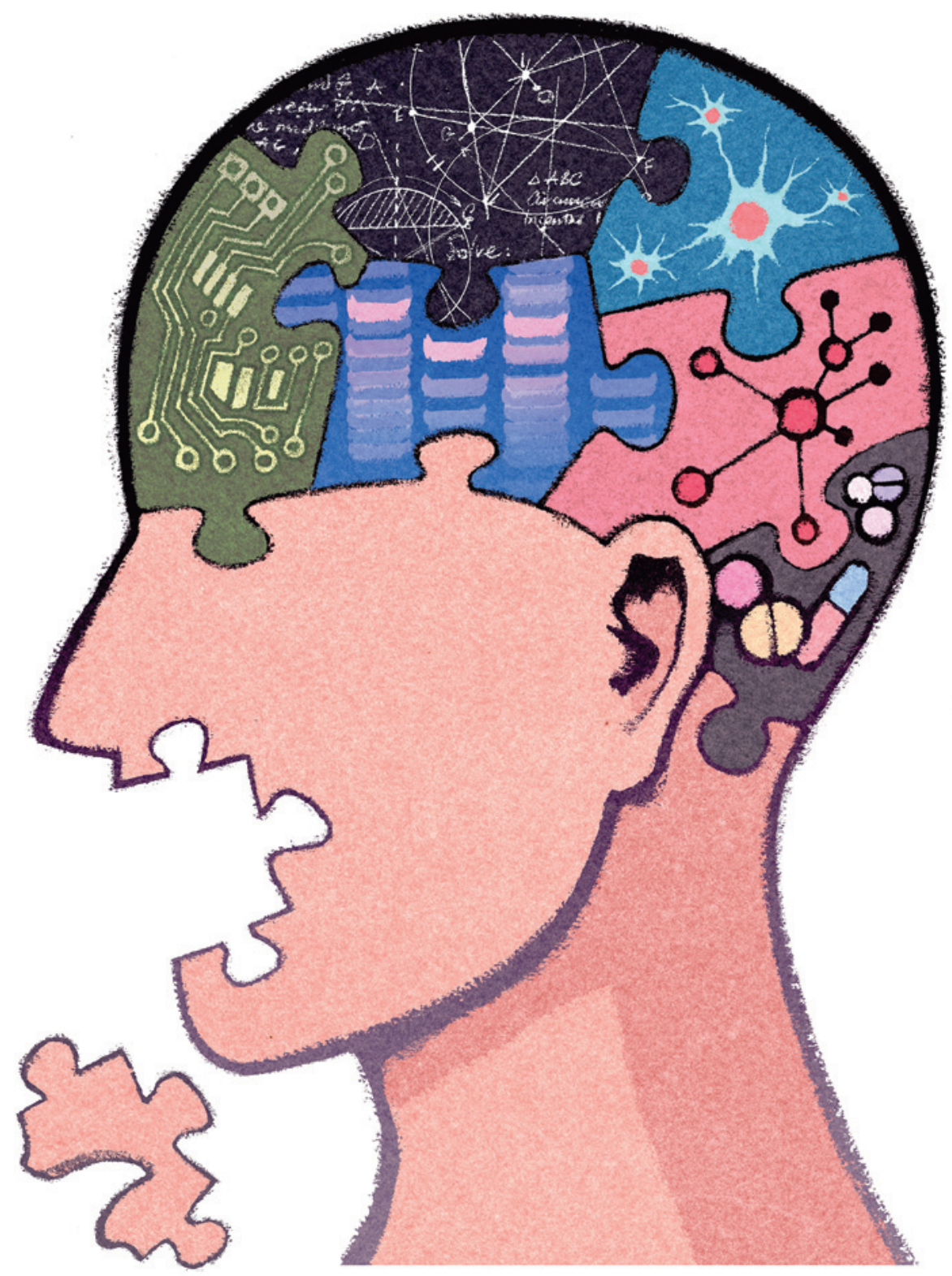

A call for mentalhealth science

\section{Clinicians and neuroscientists must work together to} understand and improve psychological treatments, urge Emily A. Holmes, Michelle G. Craske and Ann M. Graybiel.

$\mathrm{H}$ ow does one human talking to another, as occurs in psychological therapy, bring about changes in brain activity and cure or ease mental disorders? We don't really know. We need to.

Mental-health conditions, such as post-traumatic stress disorder (PTSD), obsessive-compulsive disorder (OCD), eating disorders, schizophrenia and depression, affect one in four people worldwide. Depression is the third leading contributor to the global burden of disease, according to the World Health Organization. Psychological treatments have been subjected 